\title{
A Review on Optimization of Process Parameters of Abrasive Water jet Machining of Natural Fiber Based Polymer Composites
}

\author{
P.Mani ${ }^{1}$, R. Arularasan ${ }^{2}$, R. Edison chandraseelan ${ }^{3}$ \\ ${ }^{I}$ Research Scholar, Dept. of Mechanical Engineering, \\ University College of Engineering, Arani, Tamilnadu, India \\ ${ }^{2}$ Associate Professor, Dept. of Mechanical Engineering, \\ University College of Engineering, Arani, Tamilnadu, India \\ ${ }^{3}$ Principal consutant, Quality Inteli Pvt Ltd., Chennai, Tamilnadu, India. \\ Email: edisonphd1@gmail.com. manisirin23@gmail.com. vrarasan@gmail.com.
}

\begin{abstract}
The need of modern machining technique like AWJM is inevitable to produce complex components in the field of automobile, aerospace, marine, chemical and power plant industries. Several components have been produced using FRPCs with many intrinsic features for variety of applications. However, the influence of various parameters of AWJM on material performance is found to be scanty, the performance of NFRPCs on AWJM process has not been explored exhaustively. Taking all these aspects into account, the current review formulates a study of the AWJM performance of various NFRCs such as banana, coconut sheath and jute with respect to varying factors and to find the optimum conditions for AWJM operation. There are so many process parameters which affect the quality of machined surface cut by AWJM. But, the traverse speed, hydraulic pressure, stand-off distance, Abrasive flow rate and type of abrasive and performance measures such as Material Removal Rate (MRR), Surface Roughness (SR), Kerf width, Depth of cut are considered important .
\end{abstract}

Keywords: Fibre Reinforced Composite, Natural Fibre Reinforced Polymer Composites, Polymer Matrix Composite, Abrasive Water jet Machining(AWJM), Surface roughness (SR), Material removal rate (MRR), kerf width, Depth of cut (DOC).

\section{INTRODUCTION}

A detailed literature review has been carried out, taking all the recent developments in the field study of AWJM into account. The findings seen in the literature for the following aspects are presented[1-10]:

1. Mechanical properties of NFRPCs

2. Optimization of machining parameters

3. Measurement of quality characteristics

\subsection{Mechanical Properties of Natural Fibre Based} Polymer Composites

Global booming in the direction of the development of sustainable green materials has provided the motivation for the composite designers for the utilization of recycling components[1] Thakur et al.

[2] have reviewed the optimum usage of raw natural fibers as indispensable elements in polymers for developing novel affordable eco-friendly composites with properties like acceptable specific strength, low density, high toughness, good thermal properties, and biodegradability. This is an emerging field of research in polymer engineering.

Dittenber et al. [3] have observed the surface treatment of fibers and improving the fiber/matrix interface. Their positive economic and environmental outlook, as well as their unique ability in meeting human needs worldwide, natural composites exhibit a good potential for use in infrastructure applications.

Natural fibres that can replace glass in fibre reinforced plastics [4] natural fibres (sisal, kenaf, hemp, jute and coir) reinforced polypropylene composites are processed by compression moulding and the tensile modulus, impact strength and the ultimate tensile stress of kenaf reinforced polypropylene composites are increases with increasing fibre weight fraction.

A study of the characterization and utilization of natural coconut fibres composites studied in [5] showed coir fibre volume fraction of $60 \%$ as a good choice in this investigation. Lower or higher than $60 \%$ of the fibre volume fraction could reduce the tensile strength of the composites.

[6] The impact behavior of short and continuous fiberreinforced polyester composites were studied by Wong et al. experimented the coir-polyester composite with the addition of sand filler, with $40 \%, 50 \%$, and $60 \%$ of volume fractions and fiber lengths of 3,7 , and $10 \mathrm{~mm}$. Results show improvement in impact strength with fiber content and fiber length. In addition, longitudinal fiber mats always exhibit a better impact toughness compared to transverse fiber mats.

Mechanical, thermal and dynamic mechanical properties of untreated (raw) and treated coconut sheath fiber reinforced epoxy composites were studied by 


\section{E-ISSN: 2321-9637 \\ Available online at www.ijrat.org}

suresh kumar et al. [7]. Treated coconut sheath fiber reinforced epoxy composite (TCSE) was seen that they possessing higher mechanical strength and thermal stability compared to untreated (raw) coconut sheath fiber reinforced epoxy composite (UTCSE).

Alavudeen et al. [8] report the minimum stress development at the interface of composites due to the distribution of load transfer along fiber direction. Moreover, alkali $(\mathrm{NaOH})$ and sodium lauryl sulfate (SLS) treatments provide an additional improvement in mechanical strength through enhanced interfacial bonding. The surface modification of cellulose fibres was studied by Belgacem et al.

[9] when cellulose fibers are used as reinforcing elements in composite materials, the cellulose fibres get low interfacial compatibility with hydrophobic polymeric matrices, as well as with a loss of mechanical properties after moisture uptake. Reduction in the hydrophilic character of cellulose fibres and improvement in the strength of their adhesion to the matrix, require undertaking of a structural modification of their surface [10].

Adhesion of an adequate degree between the surface of hydrophilic ligno-cellulosic natural fibers and the polymer matrix resin is usually desired for achievement of optimum performance of the biocomposite, Mohanty et al. [11] have analyzed the various treatments like, Dewaxing, alkali treatment, isocyanite treatment, peroxide treatment, vinyl grafting, bleaching, acetylation, and found treatment with coupling agents as useful in the improvement of fiber-matrix adhesion in natural fiber composites.

Rong et al. [12] have done investigation of the interfacial effect on the impact performance of sisal fiber reinforced epoxy composites. In the case of unidirectional laminates, an optimum fiber treatment showed the ability to provide increased affinity between fiber bundles and matrix and a decreased intercellular adhesion [13].

Cao et al. [14] have presented the bagasse fibre fibre after alkali treatment of $1 \% \mathrm{NaOH}$ solution treated fibres showed a maximum improvement. Approximately $13 \%$ improvement in tensile strength, $14 \%$ in flexural strength and $30 \%$ in impact strength respectively had been found. Following alkali treatment, increase in strength and aspect ratio of the fibre was found contributing to the enhancement in the mechanical properties of the composites [15].

Considerable work has been carried out in the recent past using NFRPCs in various manufacturing applications such as automobile, aerospace, construction and electronic industries [16]. Simultaneously, factors like hydrophilic nature and the presence of unwanted contaminants on natural fibre surface reduced workability of NFRPCs in a varity of applications [17]. Several studies on the subject of overcoming these drawbacks using natural fibres with different chemical treatments that demonstrated enhancement of various engineering properties have been reported [18].

In an earlier study, the authors have reported the enhanced mechanical strength as a result of the improved interfacial adhesion between the CS fibre and polyester matrix [19]. In another work, the authors have made a comparative study of glass/polyester composite and untreated CS/polyester composites on AWJM [20].

[21] The fibre content of $50 \pm 2$ wt. $\%$ was identified as an optimum fibre loading, as it offers better mechanical properties.

Pothan et al. [22] studied that the tensile, impact, flexural properties and aging behavior of short banana fiber reinforced polyester composites. A maximum tensile strength was observed at $30 \mathrm{~mm}$ fiber length while the impact strength provide the maximum value for $40 \mathrm{~mm}$ fiber length. Further the effect of fiber length and fiber content on the mechanical properties of banana fiber/epoxy composite was studied by Venkateshwaran et al. [23] their observation was that the main factors that influence the properties of composite are fiber length and content.

Haneefa et al. [24] examined the utilization of plant fibers, banana fiber-reinforced composites that represent the most important areas. The influence of fiber content, fiber loading, and hybrid effect on the mechanical properties such as tensile strength, Young's modulus, elongation at break, and flexural properties were seen having improved as the fiber loading (vol\%) increases.

Mechanical, thermal and dynamic-mechanical behavior of banana fiber reinforced polypropylene nano composites was studied by sanjoy el al. [25] result of analysis revels an increase in storage modulus $\left(\mathrm{E}^{\prime}\right)$ and damping factor $(\tan \delta)$, conforming the strong interaction between nanoclay/banana fiber and MA-g$\mathrm{PP}$ in the fiber-reinforced nanocomposites systems.

Amico et al. [26] focused on the mechanical properties of pure sisal, pure glass, and hybrid sisal/glass compression-molded composites. The likelihood of sae hybrid composites of exhibiting properties close of pure glass depending on the type of loading and stacking sequence was observed.

Fuqua el al. [27] have described the use of bio-based fibers as composite reinforcement, specifically on the varieties of natural fibers, and the resultant properties from their constituents and hierarchal structures. Mohanty et al. [28] have reviewd the jute composites, with jute fiber as an important agricultural product.

Ahmed et al [29] ehave done evaluation of the effect of hybridization on mechanical properties of untreated (as 


\section{E-ISSN: 2321-9637 \\ Available online at www.ijrat.org}

received) woven jute and glass fabric-reinforced isothalic polyester composites using the hand lay-up technique. They observed a significant improvement after the addition of $16.5 \mathrm{wt} \%$ glass fiber, in a total fiber weight fraction of $42 \%$ that enhanced the tensile, flexural, and interlaminar shear strength.

Jute fabrics were treated with $\gamma$-methacryloxy propyltrimethoxysilane $(\gamma$-MPS $)$ for making improvements to the adhension between the jute fabric and polyester alkali treated fabric. $0.3 \%$ silane-treated jute/polyester composites exhibited superior improvements in terms of flexure properties among the fabricated composites [30]. A study of the mechanical properties, dynamic properties, and the effect of fiber treatments for jute fiber reinforced polymer composite materials manufactured using hand layup method was made [31].

Dash et al. [32] made on indept study of the Novel low-cost jute- polyester composites thermal behavior, Jute-polyester composites were fabricated with untreated (control) and bleached slivers JPH (B) with $60 \%$ loading of fiber by weight. The overall thermal stability of $\mathrm{JPH}(\mathrm{C})$ was found to be better than that of JPH (B).

Dynamic mechanical and thermal analysis of vinylester-resin-matrix composites reinforced with untreated and alkali-treated jute fibres were studied by dipa ray el. [33] a very high $\tan \delta$ value of the resin decrease in the composites, indicating the damping capacity of the composites by the addition of the fibers.

\subsection{Optimization of Process Parameters}

Wang et al. [34] found AWJM as a unique 'cold' cutting technology are as a viable and effective alternative for polymer matrix composite processing with good productivity and kerf quality. Trends of kerf quality with respect to the input parameters were also seen. They recommended the use of process control and optimization for to predicting quality characteristics. Kerf profile generated by AWJ was seen as different due to changes in the cutting parameters [35].

[36] AWJ cutting can produce good quality kerf at high production rates with proper selection of the cutting parameters. An experimental study in abrasive waterjet (AWJ) machining has been presented [37] towards with the analysis of the machining parameters towards improvement to cutting performance. [38] have suggested the predictive mathematical models for a major cutting performance measures that are essential for the optimization of the AWJ cutting process.
Abhishek et al. [39] report the harmony search (HS) algorithm as quite efficient in searching for optimal process parameters at less computational effort as compared to genetic algorithm due to diversity in search mechanism.

Deris et al. [40] have created the hybridization model of support vector machine (SVM) and grey relational analysis (GRA) in predicting optimum value surface roughness of AWJ machining process. GR-SVM presents results with accuracy better than conventional SVM as it removes the redundant features and irrelevant element from the experimental datasets. Wibowo. [41] reviewed the hybrid GR-SVM for prediction of surface roughness in abrasive water jet machining.

KOK et al. [42] proposed genetic expression programming (GEP) for the prediction of surface roughness in AWJ machining of $7075 \mathrm{Al}$ alloy composites reinforced with $\mathrm{A} 12 \mathrm{O} 3$ particles. Different models for the output variables were predicted on the basis of training data set using GEP and the accuracy of the best model was proved with testing data set.

Purusothaman et al. [43] have done experiments based on L27 orthogonal array. Pressure, standoff distance, and transverse feed rate have been considered as input parameters. Surface roughness and kerf angle as output parameters. Gravitational search algorithm (GSA) was employed to identify the best possible combination of AWJM parameters. Regression model was used for the development of the surface roughness and kerf angle model for Al-NiTi and Al-NiTi-nano SiC composites.

Shahrajabian et al. [44] experimented on CFRP conducted to obtain surface roughness, delamination factor and thrust force values based on the full factorial design of experiments, and then analysis of variance (ANOVA) is performed. The predictive models for outputs were created using the Response Surface Method (RSM) taking advantage of the experimental data.

Feito et al. [45] proposed response surface methodology and a multi-objective optimization strategy for the optimum selection of design parameters for the aforementioned output variables collectively. Such knowledge may be useful to explore further improvements toward defect-free machining of woven Carbon FRP composites.

The mechanism of delamination [46], was seen by Dhanawade et al. whose focus was on delamination and kerf geometry in abrasive water jet machining of carbon epoxy composite. The experiments were performed on the basis of response surface methodology as a statistical design of experiment approach. Analysis of variance was performed as part 


\section{E-ISSN: 2321-9637 \\ Available online at www.ijrat.org}

of the investigation of the influence of process parameters. A multi-response optimization was also performed on the basis of desirability function to minimize delamination, kerf taper ratio, and kerf top width.

Abreu e Lima et al. [47] studied the influence of traverse speed and abrasive mass flowrate in AWJM of gemstones and the results were analyzed using ANOVA.

Alberdi et al. [48] have studied the effect of the traverse feed rate, the cutting tool (combination of orifice and focusing tube diameter and abrasive mass flow rate), and the pressure over the kerf profile, taper angle, and surface roughness have been analyzed using ANOVA analysis and related to the physical parameters of the AWJ process.

Doreswamy et al. [49] studied the effect of AWJ machining parameters such as jet operating pressure, feed rate, standoff distance and concentration of abrasive on kerf width produced on graphite filled glass fiber reinforced epoxy composite by using Taguchi's L27 orthogonal arrays.

Ibraheam et al. [50] have used a statistical approach to understand the effects of the predicted variables on the response variables. Analysis of variance was performed to isolate the effects of the parameters affecting the hole making in abrasive water jet cutting of Glass FRP.

Caydas et al. [51] studied on Ra in AWJ maching process using artificial neural networks and regression model were developed to predict $\mathrm{Ra}$.

Schwartzentruber et al. [52] predicted the surface roughness in abrasive waterjet trimming of fiber reinforced polymer composites. Surface roughness is a valuable metric when assessing AWJM cut quality. The authors present 2D and 3D models capable of predicting the surface roughness during abrasive waterjet (AWJ) trimming of composite substrates. A new approach proposed for modelling the threedimensional (3D) topography produced on abrasive water jet (AWJ) cut surface has been presented [53].

Azmir and Ahsan [54] have carried out experimental investigation of the optimization of the AWJM process parameters for achieving cost effective quality product with minimum time. Their experimental results showed the cutting direction as control factor with a smaller influence. They state the type of abrasive used is the important control factor affecting $\mathrm{Ra}$. Optimization of process parameters in the abrasive waterjet machining using integrated SA-GA Method [55].
A detailed study of the effect of abrasive particle distribution in the jet on striation formation has been made by [56]. A non-invasive technique, laser Doppler anemometry has been used for the analysis of the abrasive particle distribution in the jet.

Several researchers have studied the influence of machining parameters on various materials using different optimization techniques [57]. Further, the inevitability of the study of the influence of machining parameters for achievement of the focused target has been recognized [58]. Several works [59] have been carried out using the AWJM process, and they suggest the recommendation of the optimum parameters on the quality of the cut for various FRC materials, to obtain a cost effective product [60].

Similarly, there are many works available dealing with the applicability of various optimization techniques in AWJM for identifying a suitable combination of parameters to achieve good quality machining surface. Neelesh et al. [61] indicate the importance of obtaining optimum process parameters to achieve benefits like economy and efficient utilization of advanced machining processes. The influence of parameters was analyzed using different techniques such as Taguchi technique, Genetic Algorithm (GA) and Artificial Neural Network (ANN), Simulated Annealing (SA) and Teaching-Learning-Based Optimization (TLBO) on AWJM and its allied processes (Venkata Rao and Kalyankar [62]). However, over a period of time, a number of experiments for effectiveness of confirmation test used for the statistical analysis were found with variation between the methods. Hence, it is necessary to identify the cost effective methods to obtain quality outcome with minimum time spent.

Considering all these aspects, MOORA is found as the latest and effective multi-objective optimization method for solving various decision making problems continuously addressed in the actual manufacturing practice (Chakraborty [63]) with the objective of achieving high quality low cost product.

\subsection{Measurement of Quality Characteristics}

Abrate and Walton have studied the merits and demerits of traditional and various advanced machining process on composite materials with respect to heat sensitivity, damage and tool wear. Recently, Kartal [64] has reviewed the machinability performance of various materials including composites and the importance of machining parameters using abrasive water jet. Wang has suggested AWJM as a feasible and efficient substitute for polymer based composites for improving the rate of production and performance quality. 


\section{E-ISSN: 2321-9637 \\ Available online at www.ijrat.org}

Folkes [65] has demonstrated the versatility of AWJM in different cutting processes such as drilling, milling, cleaning, peening, forming and coating removal in ecofriendly situations. Shanmugam and Masood [66] report that the fibre reinforced composites are hard to machine as they are heterogeneous due to the alternative presence of matrix and fibre

[67].Their study revealed the proof of the AWJM as a viable technique to machine such materials compared to conventional machining. Shanmugam et al. [68] have analysed the kerf characteristics and surface roughness of two different composite materials using WJM with different machining conditions such as plain water, abrasive particle and laser cutting. They found the WJM with the abrasive particles exhibiting a better cutting than the other two. Patel and Shaikh [69] suggest AWJ technology as the best method for cutting almost any material. This has been well established in terms of achieving narrow kerf width and faster rate of cutting when compared to other conventional and unconventional machining processes.

Khan and Haque [70] have performed a comparative analysis of the performance of AWJM of glass using garnet, aluminium oxide and silicon carbide. They conclude that the taper of cut increases with the increase in standoff distance they also found the garnet abrasive producing a narrow taper angle followed by aluminium oxide and silicon carbide.

AWJ found the taper inside the cut material is one of the characteristic phenomena of the AWJ cutting. Some deviations of the side walls from the plains perpendicular to the material surface can be observed and measured even in the straight line parts of trajectories [71].

Unde et al. [72] have analyzed the cutting of CFRP laminate using AWJM, various process parameters were found to have influence on the performance measures. The standoff distance and feed rate has significant influence on the kerf taper, delamination factor, and the MRR. The fiber orientation and jet pressure influence on the surface roughness of the cut.

Seo el al. [73] have done a thorough study of the aircraft structural titanium alloy $(\mathrm{Ti}-6 \mathrm{~A} 1-4 \mathrm{~V})$ machined with an abrasive waterjet (AWJ) in their investigation of its machinability under varying cutting conditions.

Ahmed et al. [74] pointout to changes in the cutting profile with the depth of the cut to form the kerf. The cutting performance of an abrasive water jet depends mainly on the abrasive particle's velocities and impact angles as well as the physical properties of the particles and the workpiece being cut.
The motion characteristics of particles play important roles on the quality and efficiency in abrasive water jet machining. The abrasive water jet flow field is simulated by computational fluid dynamics (CFD) [75].

Adyin [76] have pointed to the cost of abrasives has restricted usage of abrasive water jet (AWJ) technology in natural stone cutting applications. recycling of the abrasives makes it has more economical, effective, and environmentally friendly.

Zhong et al. [77] have carried out investigation of the glass rods, $25 \mathrm{~mm}$ in diameter, were turned by using AWJ. Effects of several process parameters on the surface quality of the machined glass surfaces have been observed. The results showed the association of higher transverse rates with an increase in material removal rate and thus an increase in surface roughness and waviness values.

Bound et al. [78] did an intensive study of the cut quality and abrasive embedment following water jet cutting of a commonly used titanium alloy, Ti6Al4V with 80 mesh garnet from five different sources (differing significantly in their hardness, crushing strength and morphology) were examined and evaluated.

Hascalik el al. [79] have suggested that the traverse speed of the jet is a significant parameter on the surface morphology and features of different regions formed in the cutting surfaces that changes according to the traverse speed. Increase in the kerf taper ratio and surface roughness with increasing traverse speed in chosen conditions was also seen.

Liu et al. [80] did the FE method analysis to estimate the volume of material removal based on the JohnsonHolmquist ceramic material (JH-2) model. Subsequently, the depth of penetration (DOP) on various abrasive waterjet (AWJ) parameters was optimized using the Finite Element models and derived mathematical equations.

Probabilistic edge-delamination strength of a thermosetting polymer composite was studied by Xiang et al. [81] Acoustic emission (AE) equipment and optical microscope were utilized to capture the edge-delamination initiation and characterize the failure modes during delaminating $\mathrm{AE}$ signals show the main failure mode during edge delaminating as interlaminar shear failure, corresponding to that predicted by numerical simulation and confirmed by SEM fractographical results in this study.

A Mathematical model was developed by Azmira et al. [82] using piecewise linear regression analysis to 


\section{E-ISSN: 2321-9637 \\ Available online at www.ijrat.org}

predict the performance of $\mathrm{Ra}$ in terms of the cutting parameters of AWJM.

Azmira et al. [83] analyzed the surface roughness and kerf taper ratio characteristics of abrasive water jet machined surfaces of glass/epoxy composite laminates, using Taguchi's design of experiments. They have confirmed the prediction of a better quality of cut through increasing in the kinetic energy of the AWJM process.

Shanmugam et al. explored the mechanism of delamination in graphite/epoxy composites under AWJM. They found the shock wave impact of the water jet as the main criterion for crack propagation leading to the delamination between the fibre and the matrix. Some attempts have already been made in the study of the effect of the jet impact velocity on delamination [84].

Many studies have been carried out on AWJM of composite materials on the aspect of kerf geometry and surface roughness. Several studies on the surface of the effect of control factors on Ta and Ra of the AWJ machining surface [85] have been reported. All these studies reveal the AWJM performance of various target material on the outcome characteristics such as $\mathrm{Ta}$ and $\mathrm{Ra}$ as well as Suitable combinations of machining parameters which are identified as significant factors affecting the machining of intricate parts [86].

\section{SUMMARY OF LITERATURE}

Based on the above literature review, the following research gaps have been identified:

(i)It is well known fact that the repairs to polymer composites was found to be one of the major problem in the composite industries. Hence, it is mandatory to identify the suitable process for overcome this drawback. AWJM was found to be one of the best machining process for producing complex shapes with less defects for composite materials. However, the performance of NFRPC on AWJM in the aspect of experimental investigation has not yet been explored.

(ii)So many investigations so far had been done on AWJM process. But most of the researchers have investigated the process parameters such as abrasive flow rate, traverse speed, standoff distance, pressure, abrasive size, orifice diameter and performance measures as Surface roughness (SR), Material removal rate (MRR), kerf width, Depth of cut (DOC).

(iii)From the literature review it is observed that mostly combinations of process parameters like abrasive size, traverse speed, standoff distance and performance measures as DOC, SR, and MRR are investigated. MRR or production is improved by increasing the traverse speed and abrasive flow rate but major problem with increasing traverse speed is that surface roughness and kerf quality are decreased. By increasing abrasive flow rate MRR increases but, decrease surface roughness. So it is important to find the optimum conditions for AWJM operation.

(iv) Most of the research on optimization had been carried out on process parameters for improvement of a single quality characteristic such as depth of cut, surface roughness, material removal rate, kerf geometry. Very few researchers have carried out study on the optimization for the power consumption, dimension accuracy and multi-objective optimization of AWJM process.

\section{REFERENCES}

[1] Biagiotti J., Puglia D. and Kenny J.M., A Review on Natural Fibre-Based Composites-Part I, Journal of Natural Fibers, 1 (2) (2008) 37-68.

[2] Thakur V.K., Thakur M.K. and Gupta R.K., Review: Raw Natural Fiber- Based Polymer Composites, Journal of Polymer Analysis and Characterization, 19 (3) (2014), 256-271.

[3] Dittenber D.B. and GangaRao H.V.S., Critical review of recent publications on use of natural composites in infrastructure, Composites Part A, 43 (2012), 1419-1429.

[4] Wambaa P., Ivens J. and Verpost I., Natural fibers: can they replace glass in fiber reinforced plastics?, Composites Science and Technology., 63 (9) (2003), 1259-1264.

[5] Wang Wei. and Huang Gu., Characterization and utilization of natural coconut fibres composites, Materials \& Design, 30 (7) (2009), 2741-2744.

[6] Wong K.J., Nirmal U. and Lim B.K., Impact behavior of short and continuous fiber-reinforced polyester composites, Journal of Reinforced Plastics and Composites, 29 (23) (2010), 34633474.

[7] Suresh Kumar S.M., Duraibabu D. and Subramanian K., Studies on mechanical, thermal and dynamic mechanical properties of untreated (raw) and treated coconut sheath fiber reinforced epoxy composites, Materials and Design, 59 (2014), 63-69.

[8] Alavudeen A., Rajini N., Karthikeyan S., Thiruchitrambalam M. and Venkateshwaren N., Mechanical properties of banana/kenaf fiberreinforced hybrid polyester composites: Effect of woven fabric and random orientation, Materials and Design, 66 (2015), 246-257.

[9] Belgacem M.N. and Gandini A., The surface modification of cellulose fibres for use as reinforcing elements in composite materials, composite Interfaces, 12 (1-2) (2005), 41-75. 
[10] Mwaikambo L.Y. and Ansell M.P., Chemical modification of hemp, sisal, jute, and kapok fibers by alkalization, Journal of Applied Polymer Science, 84 (2002), 2222-2234.

[11] Mohanty A.K., Misra M. and Drzal L.T., Surface modifications of natural fibers and performance of the resulting biocomposites: An overview

[12] Rong M.Z., Zhang M.Q. and Liu Y., Interfacial interaction in sisal/epoxy composites and its influence on impact performance, Polymer Composites, 23 (2002), 182-192.

[13] Sreekumar P.A., Selvin P.T. and Jean M.S., Effect of fiber surface modification on the mechanical and water absorption characteristics of sisal/polyester composites fabricated by resin transfer molding, Composites Part A: Applied Science and Manufacturing, 40 (11) (2009), 17771784.

[14] Cao Y., Shibata S. and Fukumoto I., Mechanical properties of biodegradable composites reinforced with bagasse fibre before and after alkali treatments, Composites Part A, 37 (3) (2006), 423-429.

[15] Das M. and Chakraborty D., Influence of alkali treatment on the fine structure and morphology of bamboo fibers, Journal of Applied Polymer Science, 102(5) (2006), 5050-5056.

[16] Fiore V., Scalici T., Nicoletti F., Vitale G., Prestipino M. and Valenza A., A new eco-friendly chemical treatment of natural fibres: Effect of sodium bicarbonate on properties of sisal fibre and its epoxy composites, Composites

[17] Balakrishnan P., John M.J., Pothen L., Sreekala M.S. and Thomas S., Natural fibre and polymer matrix composites and their applications in aerospace engineering, Advanced Composite Materials for Aerospace Engineering, (2016), 365383.

[18] Bhowmick M., Mukhopadhyay S. and Alagirusamy R., Mechanical properties of natural fibre-reinforced composites, Textile Progress, 44 (2) (2012), 85-140.

[19] Rajini N., Winowlin Jappes J.T., Rajakarunakaran S. and Jeyaraj P., Mechanical and free vibration properties of montmorillonite clay dispersed with naturally woven coconut sheath composite, Journal of Reinforced Plastics and Composites, 31 (20) (2012), 1364-1376.

[20] Kalirasu S., Rajini N., Winowlin Jappes J.T., Uthayakumar M. and Rajesh S., Mechanical and machining performance of glass and coconut sheath fibre polyester composites using AWJM, Journal of Reinforced Plastics and Composites, 34 (7) (2015), 564-580.

[21] Winowlin Jappes JT., Siva I. and Rajini N., Fractography analysis of naturally woven coconut sheath reinforced polyester composite: A novel reinforcement, Polymer Plastics Technology and Engineering, 51 (2012), 419-424.

[22] Pothan A.L., Thomas S. and Neelakantan N.R., Short Banana Fiber Reinforced Polyester Composites: Mechanical, Failure and Aging Characteristics, Journal of Reinforced Plastics and Composites, 16 (8) (1997), 744-765.

[23] Venkateshwaran N. and Elayaperumal A., Banana Fiber Reinforced Polymer Composites A Review, Journal of Reinforce Plastics and Composites, 29 (15), (2010), 2387-2396.

[24] Haneefa A., Bindu P. and Aravind I., Studies on Tensile and Flexural Properties of Short Banana/Glass Hybrid Fiber Reinforced Polystyrene Composites, Journal of Composite Materials, 42 (15) (2008), 1471-1489.

[25] Sanjoy K.N., Manoranjan B. and Smita M., Mechanical, thermal and dynamic-mechanical behavior of Banana fiber reinforced polypropelene nanocomposites, Polymer Composites, 32 (8) (2011), 1190-1201.

[26] Amico S.C., Angrizani C.C. and Drummond M.L., Influence of the stacking sequence on the mechanical properties of glass/sisal hybrid composites, Journal of Reinforced Plastics and Composites, 29 (2010), 179-189.

[27] Fuqua A.M., Shanshan Huo. and Ulven A.C., Natural Fiber Reinforced Composites, Polymer Reviews, 52 (3) (2012), 259-320.

[28] Mohanty A.K. and Misra M., Studies of jute composites, Polymer Plastics Technology and Engineering, 34 (1995), 729-792.

[29] Ahmed K.S. and Vijayarangan S., Tensile, flexural and interlaminar shear properties of woven jute and jute-glass fabric reinforced polyester composites, Journal of Materials Processing Technology, 207 (2008), 330-335.

[30] Sever K., Sarikanat M., Seki Y., Erkan G., Halis U. and Erdogan., The mechanical properties of methacryloxypropyltrimethoxy silane-treated jute/polyester composites, Journal of Composite Materials, 44 (15) (2010), 1913-1924.

[31] Elbadry A.E., Mohamed S., Aly-Hassan. and Hamada H., Mechanical Properties of Natural Jute Fabric/Jute Mat Fiber Reinforced Polymer Matrix Hybrid Composites, Journal of Advances in Mechanical Engineering, (2015), https://doi.org/10.1155/2012/354547.

[32] Dash B.N., Rana A.K. and Mishra H.K., Novel low-cost jute-polyester composites: III weathering and thermal behavior, Journal of Applied Polymer Science, 78 (2000), 1671-1679.

[33] Dipa Ray., Sarkar B.K., Das S. and Rana A.K., Dynamic mechanical and thermal analysis of vinyl ester-resin matrix composites reinforced with untreated and alkali -treated jute fibers, Composites Science and Technology, 62 (7) (2002), 911-917. 
[34] Wang J, A Machinability study of polymer matrix composites using abrasive water jet cutting technology, Journal of Materials Processing Technology,94(1999), 30-35.

[35] Wang S., Zhang S., Yuqiang Wu. and Yang F., A key parameter to characterize the kerf profile error generated by abrasive water-jet, The International Journal of Advanced Manufacturing Technology, 90 (5-8) (2017), 1265-1275.

[36] Wang J, Abrasive Waterjet Machining of Polymer Matrix Composites - Cutting Performance, Erosive Process and Predictive Models, International Journal of Advanced Manufacturing Technology, 15 (1999), 757-768.

[37] Wang J., Kuriyagawa T. and Huang C.Z., An Experimental Study to Enhance the Cutting Performance in Abrasive Waterjet Machining, Journal of Machining Science and Technology, 7 (2) (2003), 191-207.

[38] Wang J. and Liu H., Profile cutting on alumina ceramics by abrasive waterjet part 1: experimental investigation, Journal of Mechanical Engineering Science, 220 (2006), 703-714.

[39] Abhishek K., Datta S. and Mahapatra S.S., Multiobjective optimization in drilling of CFRP (polyester) composites: Application of a fuzzy embedded harmony search (HS) algorithm, Measurement, 77 (2016), 222-239.

[40]Deris A.M., Zain A.M. and Sallehuddin R., Hybrid GR-SVM for prediction of surface roughness in abrasive water jet machining, Meccanica, 48 (2013), 1937-1945.

[41] Wibowo A, A note of hybrid GR-SVM for prediction of surface roughness in abrasive water jet machining, Meccanica, 52 (8) (2017), 19891991.

[42] Kök M., Kanca E. and Eyercioğlu Ö., Prediction of surface roughness in abrasive waterjet machining of particle reinforced MMCs using genetic expression programming, International Journal of Advanced Manufacturing Technology, 55 (2011), 955-968.

[43] Purusothaman M., Manivannan J., Balakiruthiha S., Jeya Prakash K., Rajini N., Sultan M. T. H. and Rajesh S., Machinability performance of AlNiTi and Al- NiTi-nano SiC composites with parametric optimization using GSA, Journal of Australian Ceramic Society, 53 (2) (2017), 599609.

[44] Shahrajabian H. and Farahnakian M., Modeling and multiconstrained optimization in drilling process of carbon fiber reinforced epoxy composite, International Journal of Precision Engineering and Manufacturing, 14 (10) (2013) 1829-1837.

[45] Feito N., Milani A.S. and Muñoz-Sánchez A., Drilling optimization of woven CFRP laminates under different tool wear conditions: a multi- objective design of experiments approach, Structural and Multidisciplinary Optimization, 53(2) (2016), 239-251.

[46] Irina Wong M.M., Azmil., Lee C.C. and Mansor A.F., Kerf taper and delamination damage minimization of FRP hybrid composites under abrasive water-jet machining, International Journal of Advanced Manufacturing Technology, 94 (5-8) (2018), 1727-1744.

[47] Abreu e Lima.C.E, Lebrón R., Souza A.J., Ferreira N.F. and Neis P.D., Study of influence of traverse speed and abrasive mass flow rate in abrasive water jet machining of gemstones, International Journal of Advanced Manufacturing Technology, 83 (1) (2016), 77-87.

[48] Alberdi A., Artaza T., Suárez A., Rivero A. and Girot F., An experimental study on abrasive waterjet cutting of CFRP/Ti6Al4V stacks for drilling operations, International Journal of Advanced Manufacturing Technology., 86 (1-4) (2016), 691-704.

[49] Doreswamy D., Shivamurthy B., Anjaiah D. and Sharma N.Y., An investigation of abrasive water jet machining on graphite/glass/epoxy composite, International Journal of Manufacturing Engineering, (2015),doi:http://dx.doi.org/10.1155/2015/62721

[50] Ibraheam H.M.A., Iqbal A. and Hashemipour M., Numerical optimization of hole making in GFRP composite using abrasive water jet machining, Journal of the Chinese Institute of Engineers, 38 (1) (2015), 66-76.

[51] Caydas U. and Hascalik A., A study on surface roughness in abrasive waterjet machining process using artificial neural networks and regression analysis method, Journal of Materials Processing Technology, 202 (1-3) (2008), 574-582.

[52] Schwartzentruber J., Spelt J.K. and Papini M., Prediction of surface roughness in abrasive waterjet trimming of fiber reinforced polymer composites, International Journal of Machine Tools and Manufacture, 122 (2017), 1-17.

[53] Vikram G. and Ramesh Babu N., Modelling and analysis of abrasive water jet cut surface topography, International Journal of Machine Tools and Manufacture, 42 (2002), 1345-1354.

[54] Azmir M.A. and Ahsan A.K., Investigation on glass/epoxy composite surfaces machined by abrasive water jet machining, Journal of Materials Processing Technology, 198 (1-3) (2008), 122128.

[55]Zain A.M., Haron H. and Sharif S., Optimization of process parameters in the abrasive waterjet machining using integrated SA-GA, Applied SoftComputing, 11 (2011), 5350-5359.

[56] Chen F.L. and Siores E., The effect of cutting jet variation on surface striation formation in abrasive 
water jet cutting, Journal of Materials Processing Technology, 135 (2003), 1-5.

[57] Anish N. and Kumanan S., Multi performance optimization of abrasive water jet machining of Inconel 617 using WPCA, Journal Materials and Manufacturing processes, 32 (2016), 693-699.

[58] Jani S. P., Senthil Kumar A., Adam Khan M. and Uthaya Kumar M., Machinablity of Hybrid Natural Fiber Composite with and without Filler as Reinforcement, Journal Materials and Manufacturing Processes, 31 (10) (2016), 13931399.

[59] Arola D. and Ramulu M., A study of kerf characteristics in abrasive water jet machining of graphite/epoxy composite, Journal of Engineering Materials and Technology, 118 (2) (1996), 256265.

[60] Li H. and Wang J., An experimental study of abrasive waterjet machining of Ti-6Al-4V, International Journal of Advanced Manufacturing Technology, 81(2015), 1-9.

[61] Neelesh K.J., Jain V.K. and Kalyanmoy Deb., Optimization of process parameters of mechanical type advanced machining processes using genetic algorithms, International Journal of Machine Tools and Manufacture, 47 (6) (2007), 900-919.

[62] Venkata Rao R. and Kalyankar V.D., Optimization of modern machining processes using advanced optimization techniques: a review, International Journal of Advanced Manufacturing Technology, 73 (5) (2014), 1159-1188.

[63] Chakraborty S, Applications of the MOORA method for decision making in manufacturing environment, International Journal of Advanced Manufacturing Technology, 54 (9-12) (2011), 1155-1166. P4-16

[64] Abrate S. and Walton D., Machining of composite materials part-II: Non-traditional methods, Composites Manufacturing, 3 (2) (1992), 85-94.

[65] Fuat Kartal, A review of the current state of abrasive water-jet turning machining method, International Journal of Advanced Manufacturing Technology, 88 (1-4), (2017) 495-505.

[66] Janet Folkes, Waterjet-an innovative tool for manufacturing. Journal of Materials Processing Technology, 209 (20) (2009), 6181-6189.

[67] Shanmugam D.K., Nguyen T. and Wang J., A study of delamination on graphite/epoxy composites in abrasive waterjet machining, Composites: Part A, 39 (2008), 923-929.

[68] Shanmugam D.K., Wang J. and Liu H., Minimisation of kerf tapers in abrasive waterjet machining of alumina ceramics using a compensation technique, International Journal of Machine Tools and Manufacture, 48 (14) (2008), 1527-1534

[69] Shanmugam D.K., Chen F.L., Siores E. and Brandt M., Comparative study of jetting machining technologies over laser machining technology for cutting composite materials, Composite Structure, 57 (1-4) (2002), 289-296.

[70] Patel S.R. and Shaikh A.A., A review on machining of fiber reinforced plastic using abrasive water jet, International Journal of Innovative Technology \& Adaptive Management, 1 (3) (2013), 2347-3622.

[71] Khan A.K. and Haque M.M., Performance of different abrasive materials during abrasive water jet machining of glass, Journal of Materials Processing Technology, 191 (1-3) (2007), 404407.

[72] Hlav'a c L.M., Hlav'a cov'a I.M., Geryk V. and Plan`c'ar 'S., Investigation of the taper of kerfs cut in steels by AWJ, International journal of advanced manufacturing technology, 77 (9-12) (2014), 1811-1818.

[73] Unde P.D., Gayakwad M.D., Patil N.G., Pawade R.S., Thakur D.G. and Brahmankar P.K., Experimental Investigations into Abrasive Waterjet Machining of Carbon Fiber Reinforced Plastic, Journal of Composites, (2015), doi: http://dx.doi.org/10.1155/2015/971596.

[74] Seo Y.W., Ramulu M. and Kim D., Machinability of Titanium Alloy (Ti6Al4V) by abrasive waterjets, Proceedings of the Institution of Mechanical Engineers, Part B: Journal of Engineering Manufacture, 217 (12) (2003), 17091721.

[75] Ahmed D.H., Naser J. and Deam R.T., Particles impact characteristics on cutting surface during the abrasive water jet machining: numerical study, Journal of Materials Processing Technology, 232 (2016), 116-130.

[76]Zhang X., Zhou C., Jiang L. and Rui Guo., Influence of process parameters on abrasive particle motion characteristics in abrasive water jet descaling, International Journal of Advanced Manufacturing Technology, 90 (9-12) (2017), 2741-2749.

[77] Aydin G, Recycling of abrasives in abrasive water jet cutting with different types of granite, Arabian Journal of Geosciences, 7 (10) (2014), 4425-4435.

[78]Zhong Z.W. and Han Z.Z., Turning of glass with abrasive waterjet, Journal of Materials and manufacturing processes, 17 (3) (2006), 339-349.

[79] Boud F., Carpenter C., Folkes J. and Shipway P.H., Abrasive waterjet cutting of a Ti6Al4V alloy: the influence of abrasive morphology and mechanical properties on workpiece grit embedment and cut quality, Journal of Materials Processing Technology, 210 (2010), 2197-2205.

[80] Singh P.J., Chen W.L. and Munoz J., Comprehensive evaluation of abrasive waterjet cut surface quality, Proceeding 6th American Water Jet Conference, (1991), 139-161. 
International Journal of Research in Advent Technology, Vol.7, No.5, May 2019

E-ISSN: 2321-9637

Available online at www.ijrat.org

[81]Liu D., Zhu H., Huang C., Wang J. and Yao P., Prediction model of depth of penetration for alumina ceramics turned by abrasive waterjetfinite element method and experimental study, International Journal of Advanced Manufacturing Technology, 87 (9-12) (2016), 2673-2682.

[82] Xiang-Fa Wu. and Dzenis A.Y., Experimental determination of probabilistic edge-delamination strength of a graphite-fiber/epoxy composite, Composites Structure, 70 (1) (2005), 100-108.

[83] Azmir M.A., Ahsan A.K. and Rahmah A., Effect of abrasive water jet machining parameters on aramid fibre reinforced plastics composite, International Journal of Material Forming, 2 (2008), 37-44.

[84] Azmira M.A. and Ahsan A.K., A study of abrasive water jet machining process on glass/epoxy composite laminate, Journal of Materials Processing Technology, 209 (20) (2009), 6168-6173.

[85] Hashish M, Precision drilling of composites with abrasive water jets, ASME: Machining of Advanced Composites, 45 (1993), 217-225.

[86]Dong Hu., Lin Tang C., Yong Kang. and Xiaoyong Li., An Investigation on Cutting Quality by Adding Polymer in Abrasive Water Jet, Journal Of Particulate Science and Technology, 34 (3) (2016), 352-358. 